\title{
Eliminating Maternal and Neonatal Tetanus and Promoting Clean Delivery Practices Through Disposable Clean Birth Kits
}

\author{
Syed Ahsan Raza ${ }^{1 *}$ and Bilal lqbal Avan ${ }^{2}$ \\ ${ }^{1}$ Department of Family and Community Medicine, Baylor College of Medicine, Houston, TX, United States, ${ }^{2}$ Faculty of \\ Infectious and Tropical Diseases, London School of Hygiene and Tropical Medicine, London, United Kingdom
}

Keywords: neonatal tetanus, clean birth kits, neonatal infection, immunization (vaccination), infection

\section{INTRODUCTION}

Tetanus is a vaccine-preventable acute disease manifested by instability of motor system and autonomic nervous system and is caused by a highly potent neurotoxin produced by the spore-forming bacterium Clostridium tetani that thrives in an anaerobic environment $(1,2)$. The spores of C. tetani are ubiquitous, found in soil and environment, and can contaminate wounds and abrasions. All mammals on land are affected by tetanus, and there is variation in susceptibility to the disease (2). Historically, it has been documented that primates such as monkeys, apes, and chimpanzees are more susceptible than carnivores $(2,3)$. In humans, the disease remains common in many low-resource countries where it represents a major prevention challenge. Although very rare in developed parts of world, it still presents a diagnostic and therapeutic challenge $(2,4)$.

Worldwide, tetanus contributes to a large proportion of maternal and neonatal deaths, estimated in 2008, to have caused approximately 180,000 deaths per year (1). In neonatal tetanus, the umbilical stump acts as an entry point for the bacteria after unhygienic delivery and cord care practices (2). In maternal tetanus, infection can occur after miscarriages, abortion, as well as unclean and hygienic delivery practices. Prevention is carried out through vaccination with tetanus toxoid, but since the spores of $C$. tetani are widespread in the environment, eradication is impossible. Therefore, the goal of global prevention strategies is to reach elimination of disease $(2,5)$.

Specialty section:

This article was submitted to

Children and Health,

a section of the journal

Frontiers in Public Health

Received: 01 August 2019

Accepted: 29 October 2019

Published: 21 November 2019

Citation:

Raza SA and Avan Bl (2019) Eliminating Maternal and Neonatal Tetanus and Promoting Clean Delivery Practices Through Disposable Clean Birth Kits. Front. Public Health 7:339.

doi: 10.3389/fpubh.2019.00339

\section{MATERNAL AND NEONATAL TETANUS ELIMINATION}

Neonatal tetanus (confirmed case) is defined as "a neonate with the normal ability to suck and cry during the first 2 days of life, and between 3 and 28 days of age cannot suck normally and becomes stiff or has spasms" (6). In the 1980s, even with the availability of cheap and effective prevention through maternal vaccination, high incidence rates were observed with high mortality (7). Hence, the World Health Assembly, in 1988, passed a resolution to eliminate neonatal tetanus by the year 2000, a disease that, at the time, was estimated to kill 800,000 neonates a year. The elimination of neonatal tetanus was realized as a grave public health problem and was defined as fewer than one case per 1,000 livebirths in every district or similar administrative unit in every country each year (8). By 1999, the World Health Organization (WHO), the United Nations Children's Fund (UNICEF), and the United Nations Population Fund (UNFPA) re-launched their efforts to achieve the goal of neonatal tetanus elimination. 
Since neonatal tetanus depends mainly on immunization of mother during pregnancy, the goal of elimination of maternal tetanus (defined as tetanus during pregnancy or within 6 weeks of the end of pregnancy) was also added to this initiative, which was then called "Maternal and Neonatal Tetanus Elimination Program." The deadline for elimination was extended to 2005 and was set as the cutoff year to achieve this goal that later was again shifted to $2015(8,9)$. The fourth elimination goal for maternal and neonatal tetanus is now targeted for year 2020 (8).

Implementation of the Maternal and Neonatal Tetanus Elimination Initiative has involved two main strategies: immunization and clean delivery and cord care practices (and to much extent surveillance as well) $(7,8,10)$. No formal reporting system exists for maternal tetanus, and elimination is assumed to be accomplished with elimination of neonatal tetanus (11-13). Mainly, due to high prevalence of inadequate immunization in some countries, along with unclean delivery services and inappropriate umbilical cord care, neonatal tetanus represents a high proportion of the total tetanus disease burden. Most of the neonatal deaths occur in countries from Sub-Saharan African regions and South Asia, generally in areas where poverty is rampant. In some of these regions, the main problem for mothers is access to quality antenatal health care, in addition to inadequate information about clean delivery practices, since most of the deliveries happen in home (14). Traditional practices in home deliveries that includes application of harmful substances to umbilical stump still persist even in pockets of poor localities of large urban cities where access to health care facilities are supposedly better (15-17). The fatality rate of neonatal tetanus can be as high as $100 \%$ in case of home deliveries or where deliveries are not carried out in proper health care facilities $(12,16)$. In many developing countries, the extent of burden cannot be estimated since many neonates and women die during these home deliveries and where there is no appropriate system of surveillance through which both the birth and death can be reported (5).

Neonatal tetanus is historically neglected as a health problem in developing countries (9). This is not only because it is a disease of poor that has been eliminated by many countries of the world, but for the reason that it can still pose a serious public health challenge in countries where the marginalized and displaced population sometimes lack a strong political representation, e.g., Afghan refugees in Pakistan and some of the federally administered tribal areas bordering Pakistan and Afghanistan (18-21). Traditional attitudes of people in the past such as considering deaths from neonatal tetanus as wish of God and viewing immunization campaigns with suspicion have likely contributed to the neglect in some regions of the world $(9,22,23)$. Of late, natural disasters, armed conflicts, and politically motivated fake vaccination programs by vested interests are other important factors that have disrupted a properly functioning public health infrastructure and have caused additional challenges for global prevention and elimination strategies of childhood vaccine preventable diseases including neonatal tetanus $(2,24-27)$.

To date, 14 countries have yet to achieve elimination goal in 2020 and where maternal and neonatal tetanus remains a big challenge mainly due to wars, conflicts, and politically

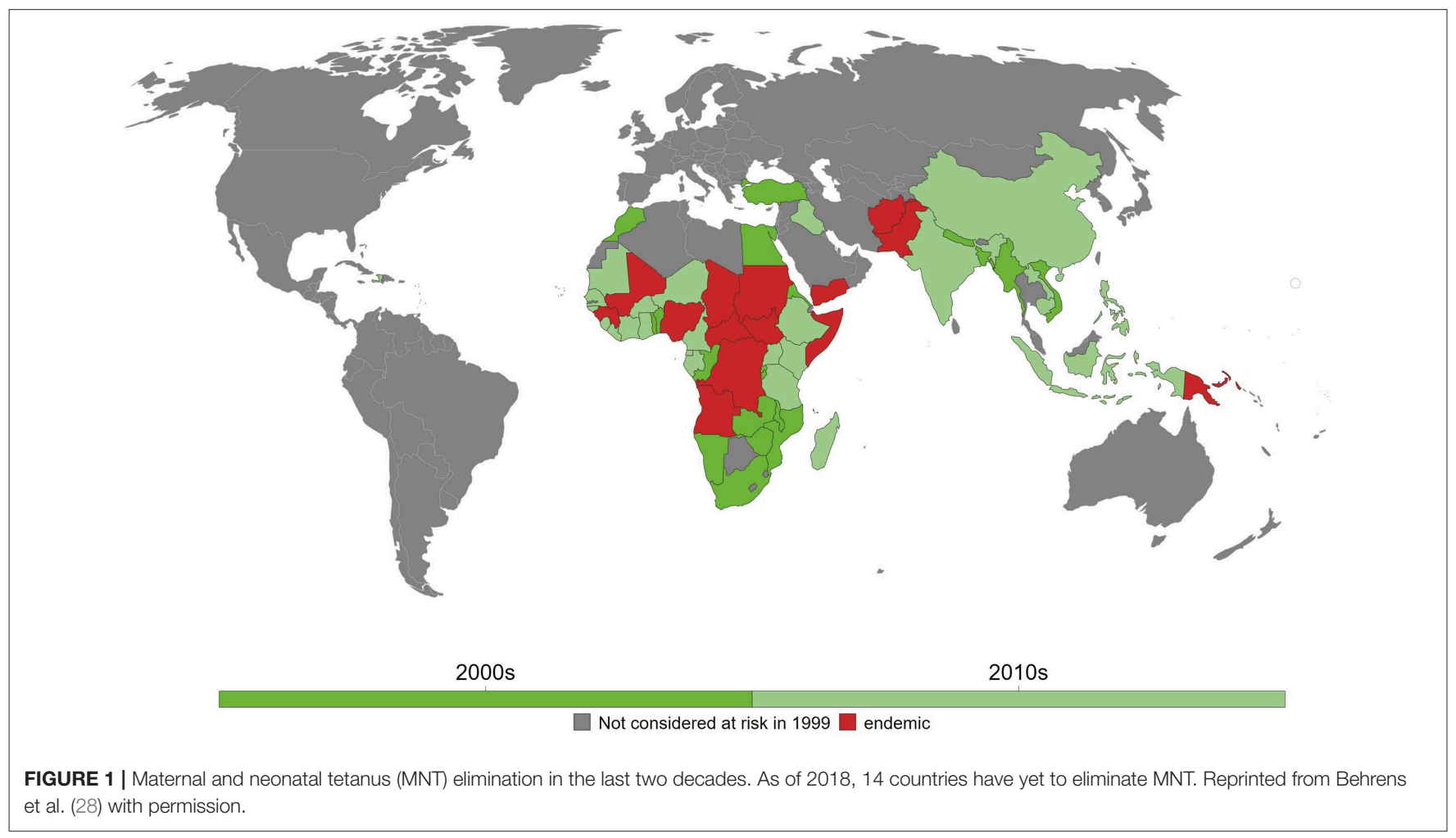


vulnerable environment. These include Afghanistan, Angola, Central African Republic, Chad, Congo, Guinea, Mali, Nigeria, Pakistan, Papua New Guinea, Somalia, Sudan, South Sudan, and Yemen (Figure 1) (28). India, as one of the largest South Asian countries, achieved the elimination goal in 2015 (29), whereas, in Africa, Kenya became one of the last countries in 2018 that has been declared free of maternal and neonatal tetanus (8).

\section{IMMUNIZATION}

One of the two main strategies for eliminating neonatal tetanus and, as a consequence, maternal tetanus is immunization. Tetanus toxoid vaccine is available as a monovalent tetanus toxoid, a bivalent toxoid combined with diphtheria or reduced diphtheria toxoid content, or a trivalent vaccine combined with diphtheria and whole cell or acellular pertussis (DTP vaccine). Other vaccine combinations with hepatitis B, Hemophilus influenzae type $\mathrm{b}$, and polio also exists $(2,30)$. As part of the Expanded Program on Immunization, WHO has recommended three doses of DTP vaccine to an infant at 2, 3, and 4 months followed by boosters at 4-7 years and 15 years of age (2, 31). To prevent neonatal tetanus, maternal immunization is recommended with two doses of tetanus toxoid 4 weeks apart during pregnancy for women who have never been vaccinated or incompletely vaccinated. In order for long-lasting maternal protection, a total of five doses should be given; a third dose should be given 6 months after the second dose and then two subsequent doses should be given 5 and 10 years later. Maternal vaccination provides protection for an estimated $84 \%$ of the neonates $(8,13)$. Figure 2 shows the percentage of maternal immunization coverage with two doses of tetanus toxoid vaccine from 1980 to 2018 in countries where neonatal tetanus is still a major public health problem. Since 2000, a decline is seen in reported cases of neonatal tetanus with this immunization coverage even though surveillance of cases may still be incomplete in resource-limited countries.

The elimination initiative for maternal and neonatal tetanus uses two immunization approaches. The first approach most commonly used is the routine immunization of pregnant women that aims to deliver two doses of tetanus toxoid 1 month apart. The second approach, known as supplementary immunization activities (SIAs) are employed in areas deemed to be high risk for neonatal tetanus where the first approach may not be effective. In SIAs, opportunities for vaccination are provided beyond the conventional antenatal settings such as school-based programs, markets, and community-based settings. Worldwide, the additional application of SIAs has been helpful in making significant progress in many countries between 1999 and 2013 $(7,32,33)$. Since maternal and neonatal tetanus occurs more in communities where there is high prevalence of unclean home deliveries practiced by traditional birth attendants, the two immunization approaches are likely to have greatest impact in the low-resource regions of the world. While supplementary immunization have been successful in increasing the coverage of vaccines in low-resource regions, particularly in conflict zones such as in Afghanistan and Somalia, these activities have recently been found to be unintentionally detrimental and disruptive to the routine health services (34). The authors have called for greater support for routine services to complement supplementary health services.

\section{CLEAN BIRTH KITS}

The second elimination strategy for maternal and neonatal tetanus is improving birth hygiene or practicing clean deliveries. The importance of clean practices during delivery has been

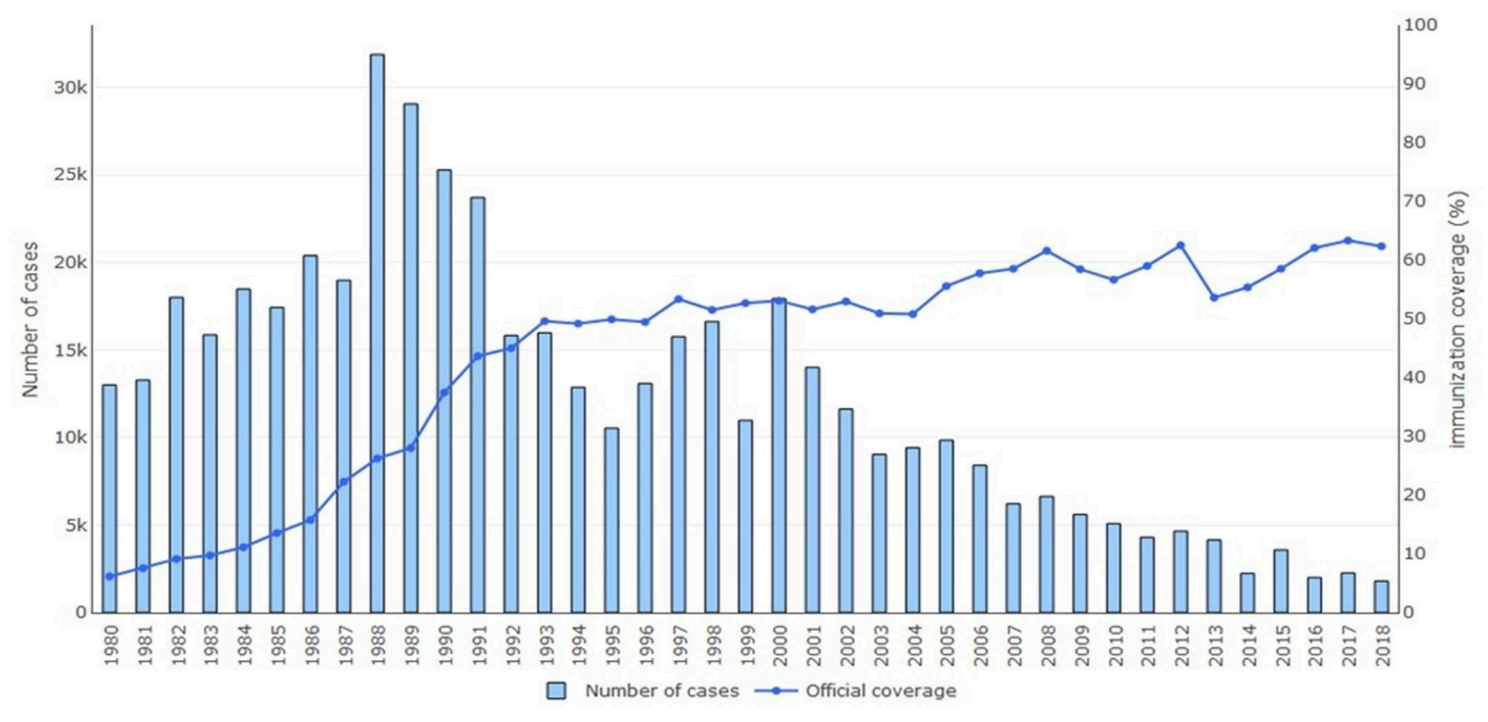

FIGURE 2 | Annual reported cases of neonatal tetanus and coverage of two or more doses of tetanus toxoid vaccine, 1980-2018. Reprinted with permission from World Health Organization (6). 


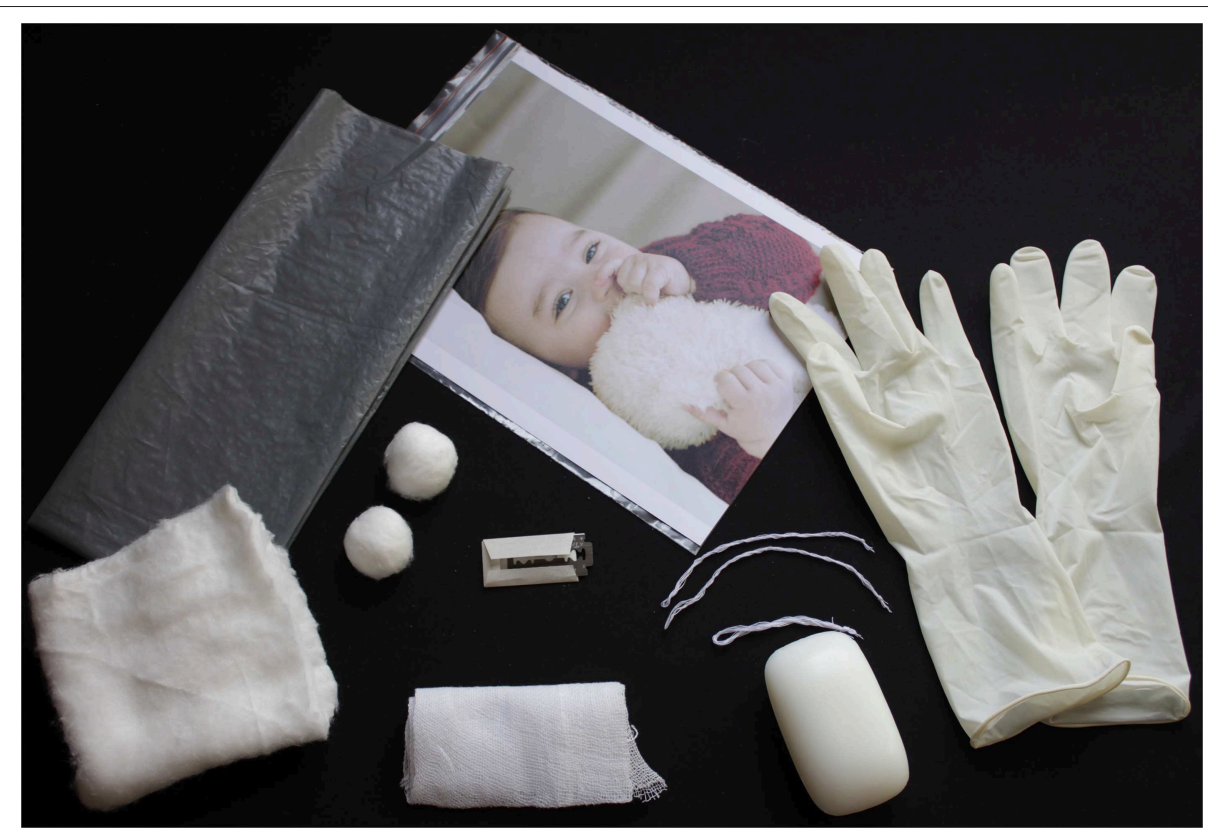

FIGURE 3 | Contents of Clean Delivery Kit to ensure clean delivery practices that includes plastic delivery sheet, a soap, blade, cord ties/ligand, spirited gauze, and, additionally, gloves (credits: Bushra Khan and Waqas Hameed).

emphasized for centuries from times of Ancient Greeks and from texts of Avicenna (35). One of the best examples in this regard is the case of child-bed fever or "puerperal sepsis" realized by nineteenth-century Hungarian physician Ignaz Semmelweis, when he demonstrated that an approach as simple as "cleaning hands" could prevent totally unnecessary deaths of mothers during delivery. The epidemic nature of infectious causes of maternal and neonatal deaths and its prevention through clean delivery practices was realized however much later after Semmelweis's death in $1865(35,36)$. Many decades later, in 1998, WHO published a review of evidence for care of umbilical cord and summarized clean delivery and cord care practices as "six cleans" (37).

High neonatal mortality rates are observed in developing countries due to neonatal umbilical cord infections. Preventions of these infections involve practicing "six cleans" along with increased coverage of tetanus toxoid immunization. However, in regions of the world where vaccination and immunization are now viewed with suspicion $(24,26)$, promotion of these six clean practices is a pragmatic step. A few elementary supplies are required for carrying out these practices, e.g., soap to wash hands and perineum, a clean blade to cut the umbilical cord, and clean thread to tie the cord $(14,38)$. Scarcity of these six clean supplies, however, may be a hindering factor in some settings, owing to "supply chain bottlenecks" or because women cannot afford to pay. However, on many occasions, when these supplies are available, there is a need for complex behavioral change to make sure that delivery attendants or traditional birth attendants in the community practice these six cleans and that there is cultural acceptability to women and their families. Therefore, universal access to clean and hygienic child delivery requires addressing the bottlenecks on both the supply and demand side of the health system. Some interventions exert effects through multiple channels, for instance, with clean birth kits, which may influence both content of care and uptake $(14,17,38)$.

WHO has been endorsing supply of clean birth kits that are disposable in resource-poor settings for many decades $(39,40)$. This is seen as a cost-effective way of providing minimum necessary birthing provisions to promote hygienic deliveries and cord care (14). These kits consist of very basic supplies for performing clean deliveries that are helpful, especially in remote areas where a hospital delivery cannot be carried out $(17,41-45)$. Clean birth kits are also highly encouraged in hospital facilities where sometimes hygienic practices are not always possible because of improper sterilization techniques and limited supply of water (17). The main utility of these disposable kits is to provide minimum but necessary supplies for carrying out a clean delivery in one affordable package, which can be cheaply available to mothers and birth attendants. The contents of these sterilized disposable packages facilitate six clean practices, which are (1) plastic delivery sheet for clean surface, (2) a soap to ensure clean hands and (3) perineum, (4) a blade for clean cutting of umbilical cord, (5) cord ties/ligand for clean tying of cord, and, finally, (6) gauze and spirit for clean post-delivery cord care. Most of these kits also consist of a pair of gloves for carrying out clean delivery. The contents of these kits can be seen in Figure 3 .

Availability of skilled birth attendants such as doctors, nurses, and trained midwives who have access to clean services in health care facilities are crucial in reducing neonatal deaths. While availability of skilled attendants is accepted as benchmark in many countries, this alone is not enough to bring down neonatal mortality in a short period of time in less developed countries 
(17). Again, to reinforce the point, regions where there is chronic lack of skilled attendants, and where traditional birth attendants practice deliveries, and where there is not enough access to clean delivery services and where water supply is in short supply, clean birth kit seems a cost-effective strategy. Meta-analyses and literature reviews on use of disposable kits $(14,38,42,46)$ have indeed provided clues on an increase in clean practices by attendants, even when it is as simple as cleaning of hands during and after child delivery. Lower incidence rates of range of infectious outcomes have been observed such as in cases of omphalitis and postpartum infections (47). By conventional standards as well as historically, the use of these cost-effective kits by birth attendants in remote community settings have shown to reduce the incidence of some of the neonatal and maternal infections in China and India $(10,48)$.

\section{DISCUSSION}

Maternal and neonatal tetanus cannot be eradicated because of the ubiquitous nature of the bacterium in the environment, and therefore continuous efforts are needed to invest in vaccination programs for its elimination. However, in some lower- to middleincome countries of the world, these elimination programs through vaccination are likely to face multiple serious challenges on a similar pattern as in the case of other vaccine-preventable diseases $(22,23,49)$. In Pakistan and Afghanistan, for example, maternal and neonatal tetanus will remain an unfinished agenda as long as there are conflict issues at the border areas along with challenges in other areas of these countries, such as inadequate surveillance, false and superstitious beliefs, high level of distrust with health care personnel, and inaccessibility to areas with militancy. Hence, new and innovative interventions are particularly needed in these low-resource settings.

In many countries, maternal and neonatal tetanus were eliminated through clean delivery practices even before vaccines were introduced; e.g., clean cord care practices through skilled delivery assistance have been shown to be an effective intervention in reducing neonatal mortality by $50-70 \%$ (50). In China, the success of eliminating maternal and neonatal tetanus in 2012 was credited to clean delivery practices and increased facility-based deliveries, without specific vaccination schemes (51). A study carried out among the Maasai tribe in East Africa has shown that interventions to improve delivery practices sharply reduced mortality from maternal and neonatal tetanus, even without vaccination programs (52). While clean practices have clearly shown to be effective in reducing mortality in regions where most of the deliveries are carried out in homes, maintaining these practices even with skilled attendants remains challenging.

Clean birth kits to ensure clean practices have shown to be a promising strategy in reducing maternal and neonatal morbidity and mortality $(38,42,53,54)$. A systematic review by Blencowe et al. suggests that these kits to improve clean practices are highly cost-effective, at an estimated US\$215 per life saved (14). Our previous study from Pakistan reports that provision of skilled attendants and clean birth kits is independently associated with reduction in neonatal tetanus. The population attributable risk for not using birth kit was $24 \%$, which means that approximately one-quarter of neonatal cases can be prevented with the use of these kits (17). In regions of the world with poor coverage of tetanus toxoid immunization, clean birth kits appear to be an effective strategy to achieve Sustainable Development Goals of reducing maternal and neonatal mortality.

The main limitation in literature regarding clean delivery practices through clean birth kits has been the lack of good quality data assessing the effect of these kits on neonatal outcomes. Since it would not be ethical to randomize expectant mothers to receive or not receive birth kits during the time of delivery, there are very few randomized trials highlighting the effectiveness of these kits. A clustered randomized trial carried out in rural Pakistan examined the effects of training traditional birth attendants with the supply of clean birth kits; however, the specific contribution of kit usage in reducing mortality could not be estimated (55). Evidence is however available regarding the use of innovative interventions such as chlorhexidine wash or wipes (for umbilical cord cleansing) compared to acceptable standard practices (15). One major challenge is that it is difficult to separate the effect of birth kits or practices from other interventions in some of these reports such as tetanus toxoid vaccinations and other health promotion approaches (14). Certain contextual/confounding factors can also affect the generalizability of these results of published reports.

Based on pooled estimates from epidemiological studies and extensive review by Blencowe et al. (38), facility-based birth compared to home birth was found to reduce the risk of death from neonatal tetanus by $70 \%$, after controlling for major confounders such as immunization coverage. Blencowe's metaanalysis also found that intervention studies that included clean birth kits were associated with improved outcomes in neonatal tetanus and omphalitis. The evidence for the effect of these kits on neonatal outcomes was however not high and the results may not be easily generalizable. All studies in the analyses included clean birth kits as part of evaluation package alongside other interventions using different delivery mechanisms and with different background characteristics, e.g., current practices, and background tetanus rates, etc.

Even though clean birth kits have shown to have the potential to improve quality of care at birth, some questions still remain. One important issue to understand is whether mothers using the kits act as a disincentive for giving birth in the hospitals. Further information can be gained through new surveys and analyses of existing research datasets in developing countries. Another important public health priority is regarding the question of cost and health system impact of adding more contents in birth kits such as disinfectants like chlorhexidine or laborinducing medications such as misoprostol for highly trained delivery attendants. Here, "Implementation Science Research" will be needed for these add-ons for additional contents. For these add-ons, extreme caution should be practiced; e.g., laborinducing medications should not be available to untrained delivery attendants. Then, there is also a question of facility-based kits in low-resource settings that could be much more extensive with the inclusion of a blood pressure device and a suction 
device with other essential drugs. Implementation research will again be required to examine advantages in their efficiency over alternative approaches.

Because of the increasing provision of vaccines, under-five mortality has been declining. However, in order to further accelerate progress toward Sustainable Development Goals in developing regions of the world, a major focus must be placed on increasing coverage of immunization and quality of antenatal care. This, however, requires a very proactive approach to invest in human resources of developing countries such as health care workers who have deep roots with their communities and who are well equipped with essential supplies for basic, safe, and clean delivery practices.

Clean birth kits have already been made available in many developing countries; however, as pointed out in Blencowe's policy brief (5), robust evaluations are lacking regarding their contribution. Moreover, these kits are also life savers in conflict or humanitarian emergencies or in settings where facility-based clean deliveries are not always possible. For countries that are already planning to promote clean birth kits or adding new contents, it will be crucial to collect data on their experiences, e.g., implementation techniques, impact, as well as costs involved.

\section{REFERENCES}

1. Owusu-Darko S, Diouf K, Nour NM. Elimination of maternal and neonatal tetanus: a 21st-century challenge. Rev Obstet Gynecol. (2012) 5:e151-7.

2. Yen LM, Thwaites CL. Tetanus. Lancet. (2019) 393:1657-68. doi: 10.1016/S0140-6736(18)33131-3

3. Roaf HE, Sherrington CS. Experiments in examination of the; locked-jaw' induced by tetanus toxin. J Physiol. (1906) 34:315-31. doi: 10.1113/jphysiol.1906.sp001160

4. Guzman-Cottrill JALC, Eriksson C, Cho YJ, Liko J. Notes from the field: tetanus in an unvaccinated child - Oregon (2017). MMWR. 68:231-2. doi: 10.15585/mmwr.mm6809a3

5. UNICEF. Elimination of Maternal and Neonatal Tetanus. (2019). Available online at: https://www.unicef.org/health/index_43509.html (accessed September 18, 2019).

6. World Health Organization (WHO). WHO Recommended Surveillance Standard of Neonatal Tetanus. (2018). Available online at: https://www. who.int/immunization/monitoring_surveillance/burden/vpd/WHO_

SurveillanceVaccinePreventable_14_NeonatalTetanus (accessed September 18, 2019).

7. Thwaites CL, Loan HT. Eradication of tetanus. Br Med Bull. (2015) 116:69-77. doi: 10.1093/bmb/ldv044

8. World Health Organization (WHO). Protecting All Against Tetanus. Guide to Sustaining Maternal and Neonatal Tetanus Elimination (MNTE) and Broadening Tetanus Protection for All Populations. Geneva: World Health Organization (2019).

9. Sidhu J, Dewan P, Gupta P. Maternal and neonatal tetanus: a journey into oblivion. Indian Pediatr. (2016) 53:1057-61.

10. Kapoor SK, Reddaiah VP, Lobo J. Control of tetanus neonatorum in a rural area. Indian J Pediatr. (1991) 58:341-4. doi: 10.1007/BF02754963

11. Roper MH, Vandelaer JH, Gasse FL. Maternal and neonatal tetanus. Lancet. (2007) 370:1947-59. doi: 10.1016/S0140-6736(07)61261-6

12. Thwaites CL, Beeching NJ, Newton CR. Maternal and neonatal tetanus. Lancet. (2015) 385:362-70. doi: 10.1016/S0140-6736(14)60236-1

13. World Health Organization (WHO). Progress Towards Global MNT Elimination. (2019). Available online at:https://www.unicef.org/ immunization/index_43509.html (accessed September 17, 2019).

\section{AUTHOR CONTRIBUTIONS}

SR carried out the literature review and wrote the first draft of the manuscript. BA provided critical revisions of the manuscript.

\section{FUNDING}

SR was supported through a Fellowship in Primary Care Research by the Health Resources and Services Administration, an agency of the US Department of Health and Human Services (grant number T32 HP10031). The funding sponsors had no role in the study design; collection, analysis, and interpretation of the data; writing of the report; or decision to submit the manuscript for publication.

\section{ACKNOWLEDGMENTS}

We would like to acknowledge Bushra Khan of Department of Psychology, University of Karachi and Waqas Hameed of Department of Community Health Sciences, Aga Khan University, Karachi for providing the image of clean birth kits from the field.
14. Blencowe H, Lawn J, Graham W. Clean birth kits - potential to deliver? Evidence, experience, estimated lives saved and cost. In: Save the Children and Immpact (2010). Available online at: https://www.healthynewbornnetwork. $\mathrm{org} /$ resource/clean-birth-kits-potential-to-deliver-evidence-experienceestimated-lives-saved-and-cost/ (accessed September 1, 2019).

15. Andrews JY, Dalal K. Umbilical cord-cutting practices and place of delivery in Bangladesh. Int J Gynaecol Obstet. (2011) 114:43-6. doi: 10.1016/j.ijgo.2011.01.025

16. Raza SA, Akhtar S, Avan BI, Hamza H, Rahbar MH. A matched case-control study of risk factors for neonatal tetanus in Karachi, Pakistan. J Postgrad Med. (2004) 50:247-51; discussion 51-2.

17. Raza SA, Avan BI. Disposable clean delivery kits and prevention of neonatal tetanus in the presence of skilled birth attendants. Int J Gynaecol Obstet. (2013) 120:148-51. doi: 10.1016/j.ijgo.2012.07.030

18. Bartlett LA, Jamieson DJ, Kahn T, Sultana M, Wilson HG, Duerr A. Maternal mortality among Afghan refugees in Pakistan, 1999-2000. Lancet. (2002) 359:643-9. doi: 10.1016/S0140-6736(02)07808-X

19. Malik MS, Afzal M, Farid A, Khan FU, Mirza B, Waheed MT. Disease status of Afghan refugees and migrants in Pakistan. Front Public Health. (2019) 7:185. doi: $10.3389 /$ fpubh.2019.00185

20. Marsh DR, Sternin M, Khadduri R, Ihsan T, Nazir R, Bari A, et al. Identification of model newborn care practices through a positive deviance inquiry to guide behavior-change interventions in Haripur, Pakistan. Food Nutr Bull. (2002) 23(4 Suppl.):109-18. doi: 10.1177/156482650202 $34 \mathrm{~S} 115$

21. Toole MJ, Waldman RJ. Prevention of excess mortality in refugee and displaced populations in developing countries. JAMA. (1990) 263:3296-302. doi: 10.1001/jama.263.24.3296

22. Hussain SA, Menezes RG, Nagaraja SB. Parents in Pakistan arrested for polio vaccine refusal: a necessary step? Lancet. (2015) 385:1509. doi: 10.1016/S0140-6736(15)60751-6

23. Hussain SF, Boyle P, Patel P, Sullivan R. Eradicating polio in Pakistan: an analysis of the challenges and solutions to this security and health issue. Global Health. (2016) 12:63. doi: 10.1186/s12992-016-0195-3

24. Ingram A, Kett M, Rushton S. Spies, vaccines and violence: fake health campaigns and the neutrality of health. Med Confl Surviv. (2011) 27:73-6. doi: 10.1080/13623699.2011.610192 
25. Jeremijenko A, McLaws ML, Kosasih H. A tsunami related tetanus epidemic in Aceh, Indonesia. Asia Pac J Public Health. (2007) 19 Spec No:40-4. doi: 10.1177/101053950701901S07

26. Kennedy J. How drone strikes and a fake vaccination program have inhibited polio eradication in Pakistan: an analysis of national level data. Int J Health Serv. (2017) 47:807-25. doi: 10.1177/0020731417722888

27. Leone T, Alburez-Gutierrez D, Ghandour R, Coast E, Giacaman R. Maternal and child access to care and intensity of conflict in the occupied Palestinian territory: a pseudo longitudinal analysis (2000-2014). Confl Health. (2019) 13:36. doi: 10.1186/s13031-019-0220-2

28. Behrens H, Ochmann S, Roser M. Tetanus. (2019). Available online at: https:// ourworldindata.org/tetanus\#citation (accessed October 1, 2019).

29. Cousins S. India is declared free of maternal and neonatal tetanus. BMJ. (2015) 350:h2975. doi: 10.1136/bmj.h2975

30. Borrow R, Tang Y, Yakubu A, Kulkarni PS, LaForce FM. MenAfriVac as an antitetanus vaccine. Clin Infect Dis. (2015) 61 (Suppl. 5):S570-7. doi: $10.1093 / \mathrm{cid} / \mathrm{civ} 512$

31. World Health Organization (WHO). Global Vaccine Action Plan 2011-2020. Geneva: WHO (2013).

32. Datta SS, Barnabas R, Sitther A, Guarenti L, Toikilik S, Kariwiga G, et al. Three cases of neonatal tetanus in Papua New Guinea lead to development of national action plan for maternal and neonatal tetanus elimination. West Pac Surveill Response J. (2013) 4:40-3. doi: 10.5365/wpsar.2013.4.1.008

33. Vandelaer J, Partridge J, Suvedi BK. Process of neonatal tetanus elimination in Nepal. J Public Health. (2009) 31:561-5. doi: 10.1093/pubmed/fdp039

34. Chakrabarti A, Grepin KA, Helleringer S. The impact of supplementary immunization activities on routine vaccination coverage: an instrumental variable analysis in five low-income countries. PLoS ONE. (2019) 14:e0212049. doi: 10.1371/journal.pone.0212049

35. Nuland S. Doctor's Plague: Germs, Childbed Fever, and the Strange Story of Ignac Semmelweis. New York: Norton \& Co (2004).

36. Raza SA. Theory of scientific investigation by Hempel and a case of Semmelweis. J Family Med Prim Care. (2017) 6:198-200. doi: $10.4103 /$ jfmpc.jfmpc_61_17

37. World Health Organization (WHO) Care of Umbilical Cord: A review of the evidence, WHO/RHT/MSM/98.4. Geneva: World Health Organization (1998).

38. Blencowe H, Cousens S, Mullany LC, Lee AC, Kerber K, Wall S, et al. Clean birth and postnatal care practices to reduce neonatal deaths from sepsis and tetanus: a systematic review and Delphi estimation of mortality effect. BMC Public Health. (2011) 11 (Suppl. 3):S11. doi: 10.1186/1471-2458-11-S3-S11

39. World Health Organization (WHO). Safe Childbirth Checklist Implementation Guide: Improving the Quality of Facility-Based Delivery for Mothers and Newborns. Geneva: WHO (2015). Available online at: https://www.who.int/ patientsafety/implementation/checklists/childbirth/en/ (accessed August 5, 2019).

40. Perry W, Bagheri Nejad S, Tuomisto K, Kara N, Roos N, Dilip $\mathrm{TR}$, et al. Implementing the WHO safe childbirth checklist: lessons from a global collaboration. BMJ Glob Health. (2017) 2:e000241. doi: 10.1136/bmjgh-2016-000241

41. Balsara ZP, Hussein MH, Winch PJ, Gipson R, Santosham M, Darmstadt GL. Impact of clean delivery kit use on clean delivery practices in Beni Suef Governorate, Egypt. J Perinatol. (2009) 29:673-9. doi: 10.1038/jp.2009.80

42. Lassi ZS, Fisher Z, Andraweera P, Cummins A, Roberts CT. Effectiveness of birthing kits for clean childbirth: a systematic review. Int Health. (2019). doi: 10.1093/inthealth/ihz022. [Epub ahead of print].

43. Montagu D, Yamey G, Visconti A, Harding A, Yoong J. Where do poor women in developing countries give birth? A multi-country analysis of demographic and health survey data. PLoS ONE. (2011) 6:e17155. doi: 10.1371/journal.pone.0017155

44. Mosha F, Winani S, Wood S, Changalucha J, Ngasalla B. Evaluation of the effectiveness of a clean delivery kit intervention in preventing cord infection and puerperal sepsis among neonates and their mothers in rural Mwanza Region, Tanzania. Tanzan Health Res Bull. (2005) 7:185-8. doi: 10.4314/thrb.v7i3.14258

45. Winani S, Wood S, Coffey P, Chirwa T, Mosha F, Changalucha J. Use of a clean delivery kit and factors associated with cord infection and puerperal sepsis in Mwanza, Tanzania. J Midwifery Womens Health. (2007) 52:37-43. doi: 10.1016/j.jmwh.2006.09.004

46. Khan AA, Zahidie A, Rabbani F. Interventions to reduce neonatal mortality from neonatal tetanus in low and middle income countries-a systematic review. BMC Public Health. (2013) 13:322. doi: 10.1186/1471-2458-13-322

47. Hundley VA, Avan BI, Braunholtz D, Fitzmaurice AE, Graham WJ. Lessons regarding the use of birth kits in low resource countries. Midwifery. (2011) 27:e222-30. doi: 10.1016/j.midw.2010.10.003

48. Hua JZ. Current status of maternal health care in China. Chin Med J (Engl). (1994) 107:388-90.

49. Shakeel SI, Brown M, Sethi S, Mackey TK. Achieving the end game: employing "vaccine diplomacy" to eradicate polio in Pakistan. BMC Public Health. (2019) 19:79. doi: 10.1186/s12889-019-6393-1

50. Ridpath AD, Scobie HM, Shibeshi ME, Yakubu A, Zulu F, Raza AA, et al. Progress towards achieving and maintaining maternal and neonatal tetanus elimination in the African region. Pan Afr Med J. (2017) 27 (Suppl. 3):24. doi: 10.11604/pamj.supp.2017.27.3.11783

51. Liu X, Yan H, Wang D. The evaluation of "Safe Motherhood" program on maternal care utilization in rural western China: a difference in difference approach. BMC Public Health. (2010) 10:566. doi: 10.1186/1471-245810-566

52. Meegan ME, Conroy RM, Lengeny SO, Renhault K, Nyangole J. Effect on neonatal tetanus mortality after a culturally-based health promotion programme. Lancet. (2001) 358:640-1. doi: 10.1016/S0140-6736(01)0 5787-7

53. Seward N, Osrin D, Li L, Costello A, Pulkki-Brannstrom AM, Houweling TA, et al. Association between clean delivery kit use, clean delivery practices, and neonatal survival: pooled analysis of data from three sites in South Asia. PLoS Med. (2012) 9:e1001180. doi: 10.1371/journal.pmed.1001180

54. Seward N, Prost A, Copas A, Corbin M, Li L, Colbourn T, et al. Using observational data to estimate the effect of hand washing and clean delivery kit use by birth attendants on maternal deaths after home deliveries in rural Bangladesh, India and Nepal. PLoS ONE. (2015) 10:e0136152. doi: 10.1371/journal.pone.0136152

55. Jokhio AH, Winter HR, Cheng KK. An intervention involving traditional birth attendants and perinatal and maternal mortality in Pakistan. $N$ Engl Med. (2005) 352:2091-9. doi: 10.1056/NEJMsa042830

Conflict of Interest: The authors declare that the research was conducted in the absence of any commercial or financial relationships that could be construed as a potential conflict of interest.

Copyright (c) 2019 Raza and Avan. This is an open-access article distributed under the terms of the Creative Commons Attribution License (CC BY). The use, distribution or reproduction in other forums is permitted, provided the original author(s) and the copyright owner(s) are credited and that the original publication in this journal is cited, in accordance with accepted academic practice. No use, distribution or reproduction is permitted which does not comply with these terms. 